\title{
PRELIMINARY NOTES ON THE LIFE-HISTORY OF ARGAS BRUMPTI, NEUMANN.
}

\author{
By Harold H. King, F.L.S., F.E.S. \\ (Government Entomologist, Anglo-Egyptian Sudan; Wellcome Tropical \\ Research Laboratories, Khartoum.)
}

Although it is now some eight years since Neumann described Argas brumpti from specimens collected by Dr. Brumpt in Somaliland, comparatively little is known of its biology. Dr. Brumpt found the ticks living in dust under ledges of rock in the dry bed of a stream frequented by porcupines ( $\left.{ }^{1}\right)$. In British East Africa they have been taken by Mr. Scholefield on the Yatta Plains $\left({ }^{2}\right)$ and in the Anglo-Egyptian Sudan they have been recorded by the writer as occurring at Gebelein $\left(^{8}\right)$. In 1913 Mr. Cunliffe, working in England, obtained eggs and larvae from specimens sent him from British East Africa, but failed to rear the latter $\left({ }^{2}\right)$. Figures of the adult female appear in the Monograph of the Ixodoidea by Nuttall, Warburton, Cooper and Robinson. The egg and unfed larva have been figured and described by Mr. Cunliffe in The Journal of Parasitology $\left({ }^{2}\right)$.

Gebelein, which, as its name implies, consists of two rocky hills or gebels, is situated on the White Nile about 200 miles south of Khartoum. These hills are sparsely clothed with trees and other vegetation, and contain numbers of caves and crevices. The fauna found on them includes leopards, hyaenas, warthogs, porcupines, honeybadgers, conies, rock pigeons, guineafowl and innumerable bats. The ticks live here among the debris-soil and rotting leaves and twigs-in the crevices between the rocks and in the caves.

A. brumpti was first found at Gebelein in 1909, when nine specimens were taken. No other opportunity of obtaining specimens occurred until August 1913, when the writer and his wife, as a result of two days' search, succeeded in capturing one adult female and 29 nymphs of various sizes. When alarmed the ticks feign death and are then exceedingly difficult to detect, especially in the dim light of the caves. In fact, by merely turning over the debris in which they were living scarcely one was obtained, and the method eventually adopted was that of gently disturbing the debris and then watching. After a short time the ticks would come out towards one to feed, and could then be seen. Of the 30 specimens taken, the adult female and 12 nymphs were put aside for breeding purposes.

The ticks in captivity. No difficulty was experienced in inducing them to feed either on man or a rabbit, even when exposed to strong light. The adult female was given a meal of human blood on 21st August, but after that it was fed on rabbits, together with the nymphs. Eggs were obtained from the female in March and again in April 1914, but all efforts to rear the resulting larvae failed. No more eggs were obtained until October 1914, by which time seven of the nymphs had reached the adult stage, five being females and two males. These females were then isolated, and all received visits from one or other of the two males. 
Mating habits. Although pairs of ticks ready to mate were kept under close observation, the act of copulation was not witnessed. Probably it takes place only at night. One male can certainly fertilise at least three females, for, as noted above, five newly matured females were bred from though only two males were available.

Oviposition. The ticks were confined in glass-bottomed pill-boxes containing a little fine dry sand. They spent their time buried in the sand and oviposited in this position. When a batch of eggs had been laid, the female remained over it and, if undisturbed, continued to brood the eggs until they hatched. For this reason it was almost impossible to ascertain when oviposition had ceased without disturbing the female.

Incubation period. The incubation period has not been accurately determined. In one instance it was about 26 days, the first eggs of the batch being laid between 17th and 18th November and the larvae appearing on 13th December.

Larva. A newly hatched larva is feeble and disinclined to move. After two or three days the chitin hardens and the proboscis, palpi and legs, which are at first colourless, acquire a bright chestnut hue. The larva then becomes more active. If breathed upon it becomes excited and runs about, apparently in search of food. Mr. Cottam, who has been in charge of the ticks, states however that they do not feed readily until about 10 days old.

Food of the larva. Attempts were made to feed the larvae obtained in April 1914 on a chick, a nestling sparrow and pigeons. They refused to take any notice of the chick, but attached themselves readily to the sparrow and pigeons. After becoming partially gorged on these hosts however they died, without dropping off. Efforts were made to feed the larvae obtained in November and December 1914 on nestling and adult sparrows, young wild doves and bats, but without success. On the sparrows they would live for several days, but, with one exception, they all die sooner or later. The exception was a larva which remained attached to a fledgling sparrow for nine days, at the end of which time, when it appeared to be almost full-fed, the sparrow escaped. The larvae refused absolutely the wild doves, and only one specimen could be induced to attach itself to a bat--this larva was dead by the following day.

It was thought that probably the guineafowl would prove to be a suitable host for the larvae, but considerable difficulty was experienced in obtaining one. Eventually one was procured through the kindness of Captain Edwardes, A.D.C. to His Excellency the Governor General, and on this bird the larvae fed readily. At first they were placed on the under side of the wing, but only one attached itself. This specimen had disappeared by the following morning. On the loose skin of the head, in the ring of wiry feathers surrounding the ear and among the short feathers on the upper part of the neck however they attached themselves readily.

Nineteen larvae attached themselves to the head of the bird on the 13th December 1914 and thirty more two days later. Twenty-six were recovered between 21 st December and Ist January. These larvae were fed on rabbits, and those surviving at the time of writing had taken five meals and moulted four times. The remainder were killed and preserved in various stages of development.

The original stock of 26 gorged larvae recovered from the guineafowl is now represented by one third-stage nymph and five fourth-stage nymphs. More larvae are 
being reared. It is the intention of the writer to describe and figure the various stages of $A$. brumpti and to give further details of its life-history when specimens have been reared to maturity. It is hoped that in the meantime these incomplete notes may be of some interest.

The writer was in the provinces from 17th December 1914 till 26th May of this year and during that period the ticks were in the charge of Mr. R. Cottam, Laboratory Assistant.

\section{References.}

1. Nutrall, G. H. F., Warburton, C., Cooper, W. F., and Robinson, L.E.A Monograph of the Ixodoidea, Part 1, Argasidae, 1908, p. 95.

2. Cunliffe, N.-Parasitology, Cambridge, vi, no. 4, Jan. 1914, pp. 379-381.

3. KING, H. H.-Fourth Report Wellcome Tropical Research Laboratories, Vol. B, 1911, p. 128. 